\title{
Impact of Preceding El Niño and the Indian Ocean Dipole on the Southern China Precipitation in Early Summer
}

\author{
Yan Li, ${ }^{1}$ Yafei Wang, ${ }^{2}$ Lin Mu, ${ }^{1}$ Qingyuan Wang, ${ }^{3}$ Jun Song, ${ }^{1}$ and Guosong Wang ${ }^{1}$ \\ ${ }^{1}$ National Marine Data and Information Service, Tianjin 300171, China \\ ${ }^{2}$ State Key Laboratory of Severe Weather, Chinese Academy of Meteorological Sciences, 46 Zhongguancun Southern Street, \\ Haidian, Beijing 100081, China \\ ${ }^{3}$ Tianjin Meteorological Observatory, Tianjin 300074, China
}

Correspondence should be addressed to Yafei Wang; yfwang@cams.cma.gov.cn

Received 31 October 2013; Accepted 22 January 2014; Published 11 March 2014

Academic Editor: Anthony R. Lupo

Copyright (C) 2014 Yan Li et al. This is an open access article distributed under the Creative Commons Attribution License, which permits unrestricted use, distribution, and reproduction in any medium, provided the original work is properly cited.

Delayed impacts of El Niño and the Indian Ocean Dipole in positive phase (P-IOD) on the South China early monsoon were investigated by observations and simulations. The most significant correlation between IOD index (IODI) and NINO3 appeared in boreal autumn. A new index (IODN3) related to the intensity of El Niño and IOD was created. Three indexes in boreal autumn were positively well correlated with the rainfall over the Yangtze River and its southern area (rain-YRBS) in next June. The most significant correlation appeared between IODN3 and rain-YRBS. Positive rain-YRBS anomalies in June tend to occur after P-IOD or El Niño solely matured in previous boreal autumn. However, when both events matured in boreal autumn, rain-YRBS anomalies tended to be more enhanced, which suggests that a delayed combined influence of both events on rain-YRBS in June was larger than that of either event alone. There was a low level anticyclonic circulation around the Philippines (PSAC) that developed in boreal autumn and was maintained until the following June when the single event occurred. However, a much stronger PSAC tended to occur when both events matured. The stronger PSAC could transport more water vapor to YRBS and cause more rainfall there in June.

\section{Introduction}

The sea surface temperature anomalies (SSTAs) (Table 1 describes all acronyms in this paper) over the tropical Pacific (TP) play an important role in affecting climate variability over East Asia through the air-sea interaction. Wang et al. pointed out that there was a delayed response of the East Asian summer atmospheric circulation to the previous El Niño [1]. They found that a strong East Asian summer monsoon was closely associated with a mature phase of the central TP warming in the preceding boreal fall or winter. In fact, the key system linking the Pacific warming and the East Asian climate was an anomalous anticyclonic circulation around the Philippine Sea (PSAC) [2].

In the last two decades of the 20th century, a phenomenon called the Indian Ocean Dipole (IOD) was found to be another strong signal of the air-sea interaction over the tropical Indian Ocean (TIO) $[3,4]$. The IOD was characterized by a pair of opposing signs of SSTAs in the western and eastern TIO. In their definition, the positive IOD (P-IOD) event was associated with a warmer water area in the western Indian Ocean (WTIO) and a colder water area in the southeastern Indian Ocean (SETIO) while the negative one was an opposite distribution of the SSTAs. The IOD events usually began to develop in boreal summer, peaked in boreal fall, and decayed rapidly in boreal winter $[3,5]$. Air-sea interaction processes in the Indian Ocean were undoubtedly involved in the monsoon dynamics; hence they were crucial for the ENSO-monsoon teleconnection [6].

Three kinds of events were noteworthy, that is, a single El Niño event (PE) or a single P-IOD event (PI) and cooccurring event (PEI). Here, a PE (PI) year was a year when an El Niño (a P-IOD) matures solely in boreal winter (fall). PEI year was a year when El Niño peaks in boreal autumn-winter and P-IOD peaks in boreal autumn co-occurrence [7-11]. The PI event may be generated by the internal physical processes 
TABLE 1: Acronym list.

\begin{tabular}{ll}
\hline Acronym & Description \\
\hline CAM3.0 & Community Atmosphere Model 3.0 \\
CTL & Control run experiment \\
IOD & Indian Ocean Dipole \\
IODI & Index of IOD event \\
IODN3 & A new index related with the intensity of SSTAs on the TP and TIO \\
NINO3 & Index of El Niño event \\
PE & A single El Niño event \\
PEI & Co-occurring event, that is, El Niño co-occurred with P-IOD \\
PI & A single P-IOD event \\
P-IOD & Indian Ocean Dipole event in positive phase \\
PSAC & A low level anticyclonic circulation around the Philippines \\
Rain-YRBS & Rainfall over the Yangtze River and its southern area \\
SETIO & Southeastern of tropical Indian Ocean \\
SEXP1 & The first sensitivity experiments to get the single influence of PE and PI \\
SEXP2 & The second sensitivity experiments to show the stability and sensitivity of the model \\
SEXP3 & The final sensitivity experiment to get the combined influence of PEI \\
SSTAs & Surface temperature anomalies \\
TP & Tropical Pacific \\
TIO & Tropical Indian Ocean \\
TWP & Tropical West Pacific \\
WTIO & Western Tropical Indian Ocea \\
Z850A & Geopotential height anomalies at 850 hPa \\
\hline
\end{tabular}

in the Indian Ocean with regard to the strong easterly wind disturbance and were independent of El Niño [12-14]. Both of the PE and PI, as well as PEI events, could greatly affect the climate variability in the local and remote regions [7, 15-17] and so on. However, studies about the delayed impact of PIOD and El Niño on the East Asian atmospheric circulation and precipitation were rare. Two questions that remain to be answered are (1) how does the PE or PI event that matures in boreal winter or autumn have a delayed influence on precipitation over South China in next June? (2) The delayed combined influence of the PEI event on the precipitation over South China in next June?

In this study, we examine the influence of the PE, PI, and PEI events that matured in boreal autumn on the precipitation over South China in June through statistical analysis and numerical simulation.

\section{Data and Methods}

2.1. Data. The National Centers for Environmental Prediction/National Center for Atmospheric Research global atmospheric reanalysis data set with $2.5^{\circ} \times 2.5^{\circ}$ resolution was the primary data set used in this study. A detailed description of the data assimilation system that produced this data set was given by Kistler et al. [18]. The monthly precipitation for 160 meteorological stations in China was provided by the National Climate Center of China [19]. All of the monthly station observational precipitation have been transformed into the grid boxes at resolutions of $1^{\circ} \times 1^{\circ}$. Monthly SSTAs data with $5^{\circ} \times 5^{\circ}$ resolution were derived using Kaplan SSTs [20]. All the observational data sets analyzed in this study are from January 1951 to December 2000. Monthly mean data are smoothed with a 3-month running average to suppress subseasonal variability. The data sets above were used to calculate the phase of the three indices and their correlations with precipitation, along with the atmospheric states associated with each event.

\subsection{Models and Experimental Setups}

2.2.1. Model Description. Diagnostic results are further verified by Community Atmosphere Model 3.0 (CAM3.0) which was a widely used, publicly available Atmospheric General Circulation Model that served as the atmospheric component of the Community Climate System Model Version 3.0. The model adopted the $\eta$-coordinate and 26 vertical layers. The nonlinear terms and the parameterized physical processes were calculated on a T42 Gaussian grid with a horizontal resolution of about $2.8125^{\circ} \times 2.8125^{\circ}$ [21]. The model includes two optional ocean models: one drives the atmosphere model by taking monthly mean SST as a boundary field, called Data Ocean Model, and the other runs in coupling with a simple ocean model. In our work we merely consider the impact of the SSTA on the atmosphere and rainfall without considering the feedback of the atmosphere to ocean. Thus, we adopted the Data Ocean Model, which drove the model atmosphere by taking monthly mean SST as a boundary field for our experiments.

2.2.2. Experimental Design. The atmospheric sensitivity to El Niño and P-IOD event forcing was examined by prescribing idealized SSTAs. A strong El Niño and P-IOD event cooccurred from May 1997 to April 1998 and both El Niño 
TABLE 2: Designs of the numerical experiment.

\begin{tabular}{|c|c|c|c|}
\hline $\begin{array}{l}\text { Experiment } \\
\text { names }\end{array}$ & Application & Forcing of SST & Duration of the integration \\
\hline CTL & Getting the model climate & $\begin{array}{l}\text { The climatological SST varying seasonally } \\
\text { within the CAM3.0 }\end{array}$ & Integration for 20 years from 1 September \\
\hline \multirow{2}{*}{ SEXP1 } & \multirow{2}{*}{$\begin{array}{l}\text { Getting the single influence } \\
\text { of PE and PI }\end{array}$} & SEXP1-PE: P-SSTA imposed over TP & \multirow{2}{*}{ Ten different integration durations } \\
\hline & & SEXP1-PI: P-SSTA imposed over TIO & \\
\hline \multirow[t]{2}{*}{ SEXP2 } & \multirow{2}{*}{$\begin{array}{l}\text { Diagnosing the stability } \\
\text { and sensitivity of the model }\end{array}$} & $\begin{array}{l}\text { SEXP2-PE: various intensity P-SSTA* } \\
\text { imposed over TP }\end{array}$ & \multirow[t]{2}{*}{ Integrated from September to next June } \\
\hline & & $\begin{array}{l}\text { SEXP2-PI: various intensity P-SSTA* } \\
\text { imposed over TIO }\end{array}$ & \\
\hline SEXP3 & $\begin{array}{l}\text { Getting the combined } \\
\text { influence of PEI }\end{array}$ & $\begin{array}{l}\text { SEXP3-PEI: P-SSTA imposed over TP } \\
\text { and TIO }\end{array}$ & Integrated from September to next June \\
\hline
\end{tabular}

${ }^{*}$ Based on P-SSTA, the imposed SSTAs were modified by adding/subtracting $0.5^{\circ} \mathrm{C}$ at all grid points over TP or modified by adding/subtracting $0.3^{\circ} \mathrm{C}$ at all grid points over TIO.

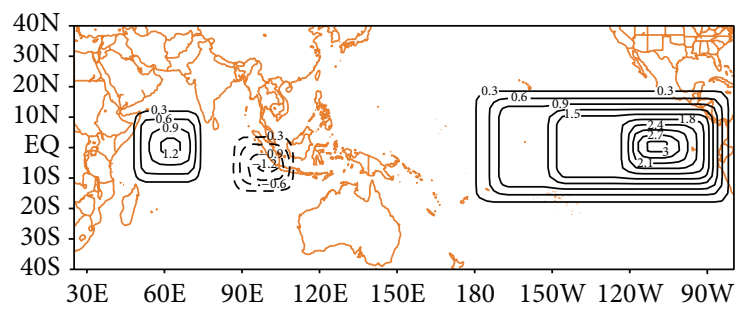

FIgURE 1: A sketch map of idealized SSTA in September over the TP and TIO regions. (unit: $\left.{ }^{\circ} \mathrm{C}\right)$.

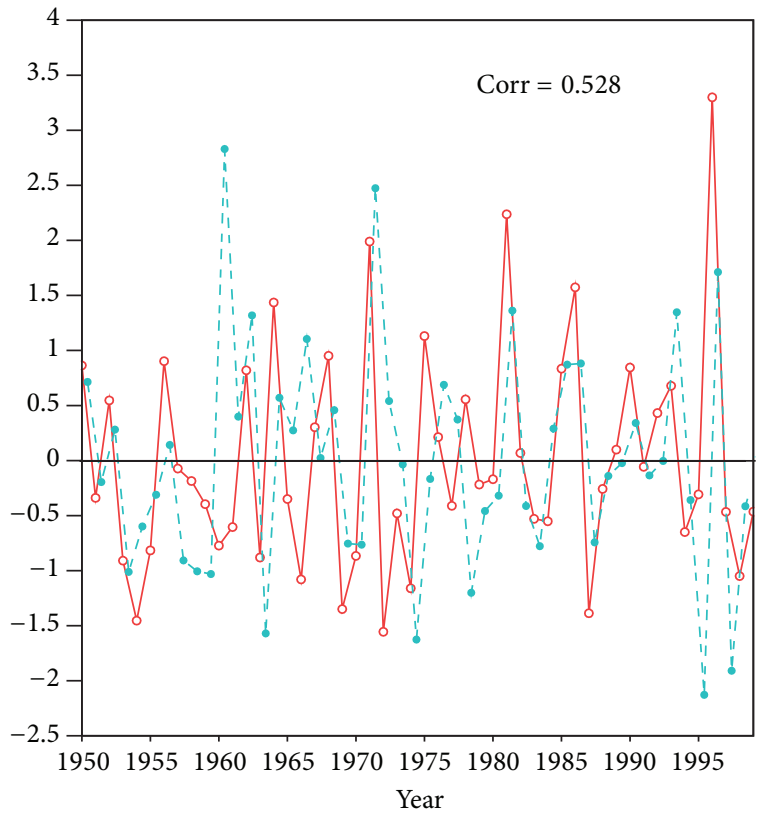

(a)

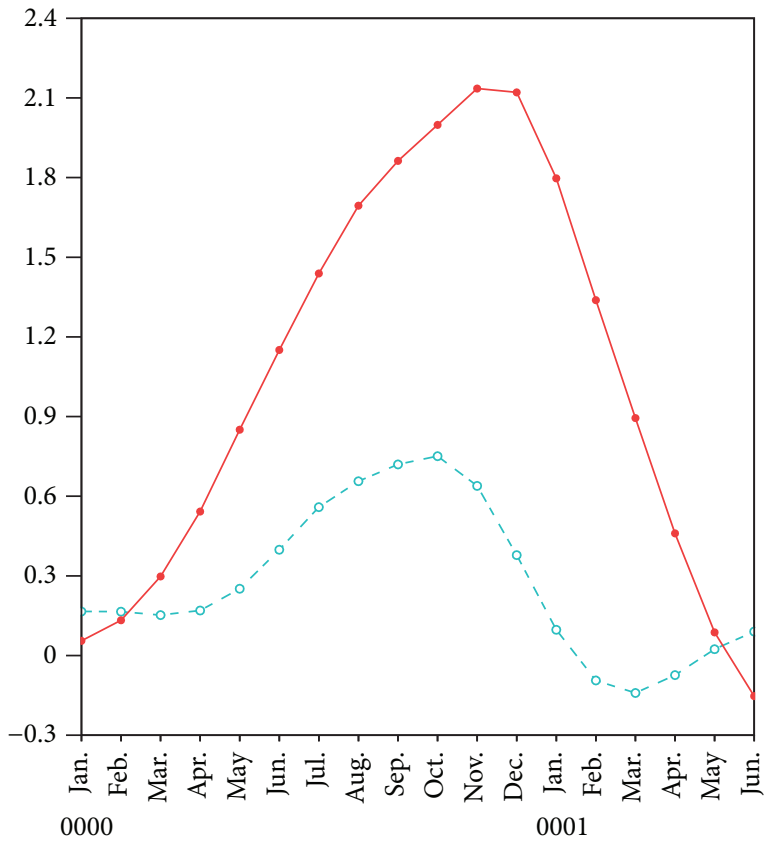

(b)

FIGURE 2: Temporal variation of normalized boreal autumn NINO3 (solid line) and IODI (dashed line) from 1951 to 2000 (a) and the temporal variation of composite monthly mean NINO3 (solid line) and IODI (dashed line) for co-occurring event years (1963, 1972, 1982, 1987, and 1997) (b). 


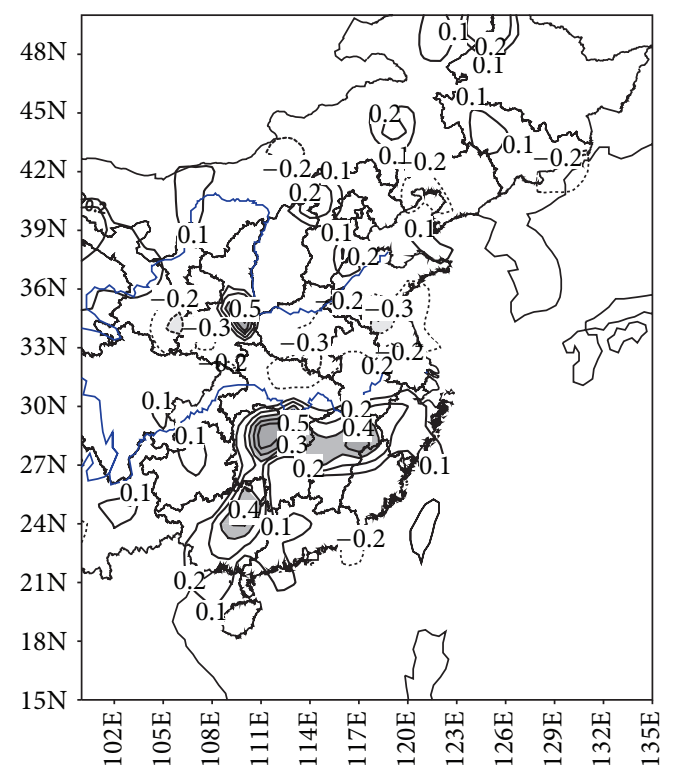

(a)

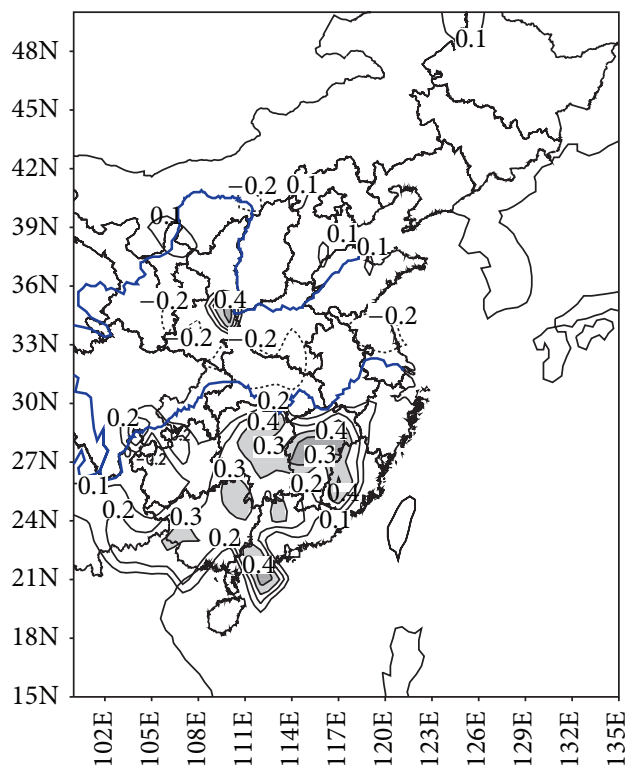

(b)

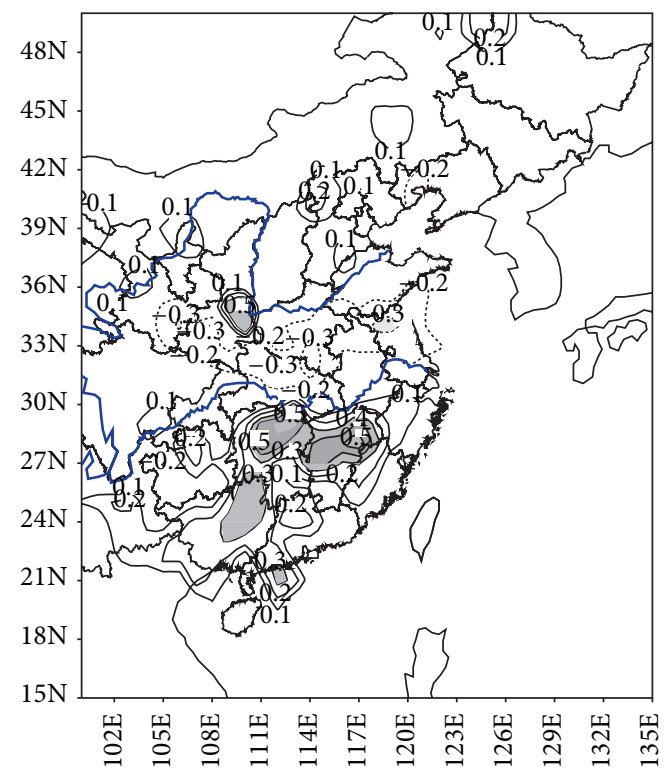

(c)

FIgURE 3: Correlations between NINO3 (a), IODI (b), and IODN3 (c) of preceding boreal fall and the precipitation over South China in June (shaded areas indicate ones exceeding 95\% confidence level).

and P-IOD events were on their peak phase in SeptemberNovember 1997. The oceanic signal during the peak time was almost strongest in the history. Thus, we chose them as the idealized imposing. The idealized SSTAs used in September are shown in Figure 1. The pattern was similar to the real-time SSTAs distribution in September 1997. The SSTAs were mainly centered at three grid points, that is, $\left(260^{\circ} \mathrm{E}, \mathrm{EQ}\right),\left(105^{\circ} \mathrm{E}\right.$, $\left.5^{\circ} \mathrm{S}\right)$, and $\left(60^{\circ} \mathrm{E}, \mathrm{EQ}\right)$ where SSTAs signals were robust in 1997. The SSTAs imposed into the model in the following months were in a similar distribution as shown in Figure 1. But the values were uniformly and correspondently reduced based on the observed SSTAs located in the three center points in Figure 1 from October 1997 to June 1998. Here, the idealized SSTAs as a boundary forcing were referred to as P-SSTA. The first sensitivity experiments (SEXP1) were designed to get the impacts of previous $\mathrm{PE}$ and $\mathrm{PI}$ in fall on rain-YRBS in June. The P-SSTAs with 10 different durations, that is, from September to next June, from October to next June,..., from May to June, and only in June were imposed over TP or TIO regions, respectively. In the second sensitivity experiments (SEXP2), we imposed various intensity P-SSTAs over TP or TIO regions, respectively. The experiments were designed to 


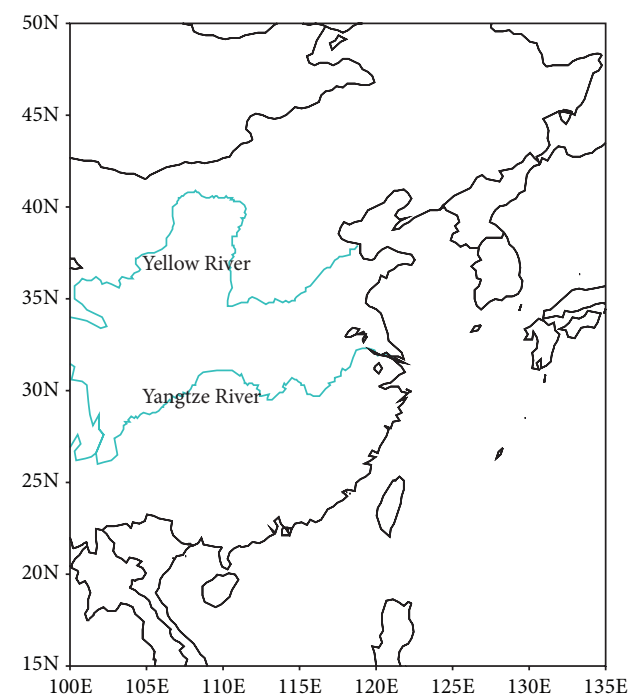

FIgURE 4: The schematic map of China with Yellow and Yangtze River marked in lines. The YRBS in this study is the Yangtze River basin and its southern area.

show the stability and sensitivity of the simulation results. In the final experiment, referred to as the SEXP3, both the PIOD type and El Nino type of P-SSTA were imposed over TP and TIO to obtain the combined influence of PEI. The designs of the numerical experiments were shown in Table 2.

The last five years of the 20-year integrations of the control run (CTL) were used to construct a 5-member ensemble mean as the model climate to reduce the nonlinear errors caused by differing initial conditions. For the sensitivity experiments the prescribed SSTAs were added to the monthly mean climatological SST field without the change of other parameters. Each scenario started from five different atmospheric initial conditions (for September 1 in the 16th20th years which were the last five years in the CTL). The integration ran for ten months (from 1 September to 30 June). The average result of the five integrations was taken as the result of each sensitivity experiment to reduce the nonlinear error caused by the different initial conditions. The atmospheric circulation and precipitation anomalies were obtained by subtracting the control experiment from the sensitivity experiments.

\section{Analysis of the Influence of PE, PI, and PEI Events on the East Asian Early Summer Monsoon}

The NINO3 used in this study was the index for measuring El Niño which was the SSTAs averaged over the Niño3 region $\left(150^{\circ} \mathrm{W}-90^{\circ} \mathrm{W}, 5^{\circ} \mathrm{S}-5^{\circ} \mathrm{N}\right)$ and the IOD index (IODI) here was defined as the SSTAs gradient between the WTIO (50$\left.70^{\circ} \mathrm{E}, 10^{\circ} \mathrm{S}-10^{\circ} \mathrm{N}\right)$ and the SETIO $\left(90-110^{\circ} \mathrm{E}, 10^{\circ} \mathrm{S}-\mathrm{EQ}\right)$ [3]. The correlations between NINO3 and IODI in boreal spring (March, April, May, (MAM)), summer (June, July, August, (JJA)), fall (September, October, November, (SON)), and winter (December, January, February, (DJF)) were calculated, respectively. The correlation between NINO3 and IODI varied with evolving seasons, which was significant starting in boreal summer and reaching peaks in boreal autumn (about 0.523, exceeding 95\% confidence level) (Figure 2(a)). However, the correlations in other seasons were weaker, especially in boreal winter (only -0.122 , below $90 \%$ confidence level). A P-IOD event in mature phase tended to accompany a matured El Niño event, for example, those in 1982 and 1997 in Figure 2(a). The temporal variations of NINO3 and IODI for both of the two events maturing in boreal autumn were shown in Figure 2(b). P-IOD reached its peak in boreal autumn and El Niño reached its peak from boreal autumn to winter, which showed a seasonal phase locking in the two events in Figure 2(b). The correlation indicated that both El Niño and P-IOD always matured in the fall. Thus, a delayed combined impact of the co-occurring events in the fall on atmospheric circulation and precipitation in early summer over South China need to be studied in detail.

To examine the combined influence of the PEI, a new index (IODN3) related to both the intensity of SSTAs in the central TP and TIO was created. The new index was defined as

$$
\begin{aligned}
\operatorname{IODN} 3= & \operatorname{SSTA} 1\left[\left(10^{\circ} \mathrm{S} \sim 10^{\circ} \mathrm{N}, 50^{\circ} \mathrm{E} \sim 70^{\circ} \mathrm{E}\right)\right] \\
& -\operatorname{SSTA}\left[\left(10^{\circ} \mathrm{S} \sim \mathrm{EQ}, 90^{\circ} \mathrm{E} \sim 110^{\circ} \mathrm{E}\right)\right] \\
& +\operatorname{SSTA}\left[\left(5^{\circ} \mathrm{S} \sim 5^{\circ} \mathrm{N}, 150 \sim 90^{\circ} \mathrm{W}\right)\right],
\end{aligned}
$$

where SSTA denoted the normalized seasonal SSTA, which werecalculated by dividing the climatological anomalies by the standard deviation.

The correlation between the NINO3, IODI, and IODN3 in the preceding boreal fall and precipitation for 160 stations of China in June were calculated, respectively. The three similar correlation coefficient distributions with a most significant correlation area over Southern China appeared in Figures 3(a), 3(b), and 3(c). The correlation coefficients exceeded 0.5 with a maximum value center of 0.62 largely covered over 


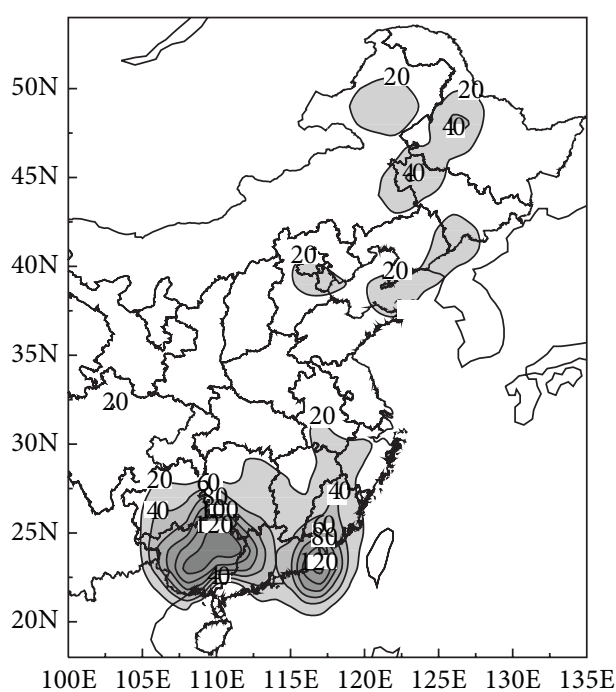

(a)

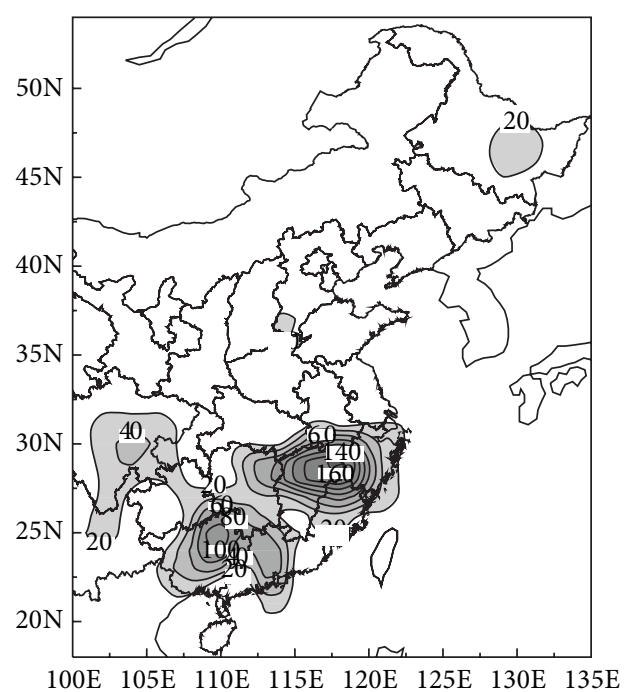

(b)

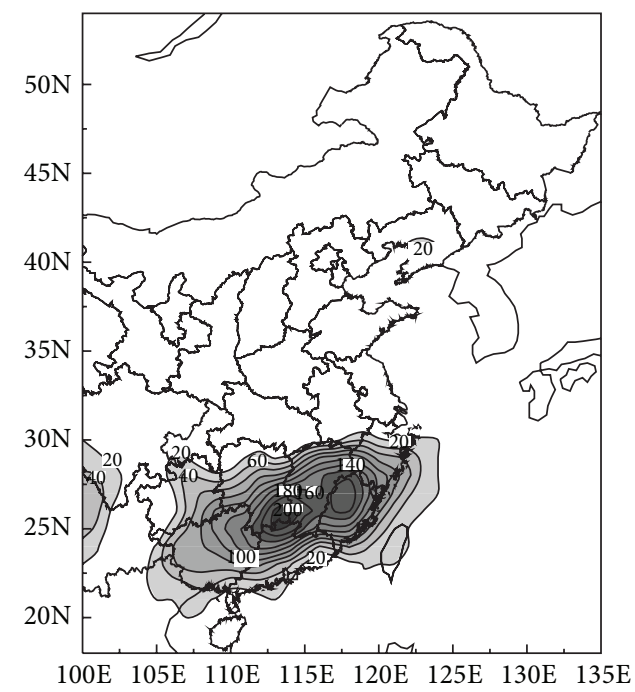

(c)

Figure 5: Composite of precipitation anomalies in next June of single El Niño years 1965, 1976, and 1991 (a); single P-IOD years 1961, 1967, and 1994 (b); and both El Niño and P-IOD co-occurring years 1963, 1972, 1982, 1987, and 1997 (c) (shaded area denotes precipitation anomaly exceeding $20 \mathrm{~mm} \mathrm{month}^{-1}$ ).

Southern China as shown in Figure 3(c). The values of the correlation coefficients covered over Southern China in Figures 3(a) and 3(b) were between 0.3 and 0.4 which were less than that in Figure 3(c) in general. The co-occurring events were more significantly correlated with the precipitation over Southern China than single events were alone.

Figure 2(a) shows that some IOD events co-occur with ENSO, while some are independent of ENSO, as shown in many other studies $[8,9,22]$. In order to study the single influence and combined influence on the rainfall over the Yangtze River basin and its southern area (rain-YRBS) (Figure 4), the composite rainfall anomalies in next June of PE years, PI years, and PEI years were plotted, respectively (Figure 5). There was a belt of large positive rainfall anomalies over the YRBS with the maximum precipitation value about
$200 \mathrm{~mm} \mathrm{month} \mathrm{h}^{-1}$ and the location of the maximum precipitation value at $\left(27^{\circ} \mathrm{N}, 117^{\circ} \mathrm{E}\right)$ in next June of the PEI years (Figure 5(c)). A similar pattern occurred in the composite of the rainfall anomalies for the previous PE and PI years (Figures 5(a) and 5(b)). However, the belt of the rain-YRBS anomalies in both figures in which the single event previously matured appeared weaker. The location of the maximum value center was at $\left(24^{\circ} \mathrm{N}, 115^{\circ} \mathrm{E}\right)$ about $120 \mathrm{~mm} \mathrm{month}^{-1}$ and $\left(28^{\circ} \mathrm{N}, 117^{\circ} \mathrm{E}\right.$ ), about $180 \mathrm{~mm}$ month $^{-1}$, respectively (Figures 5(a) and 5(b)). These results suggest that previous PEI events tended to be associated with more positive rain-YRBS in next June than PE or PI events did.

Figures 6(a) and 6(b) show the composite of geopotential height anomalies at $850 \mathrm{hPa}(\mathrm{Z} 850 \mathrm{~A})$ in the June following the PE and PI years. The positive Z850A centers were located 


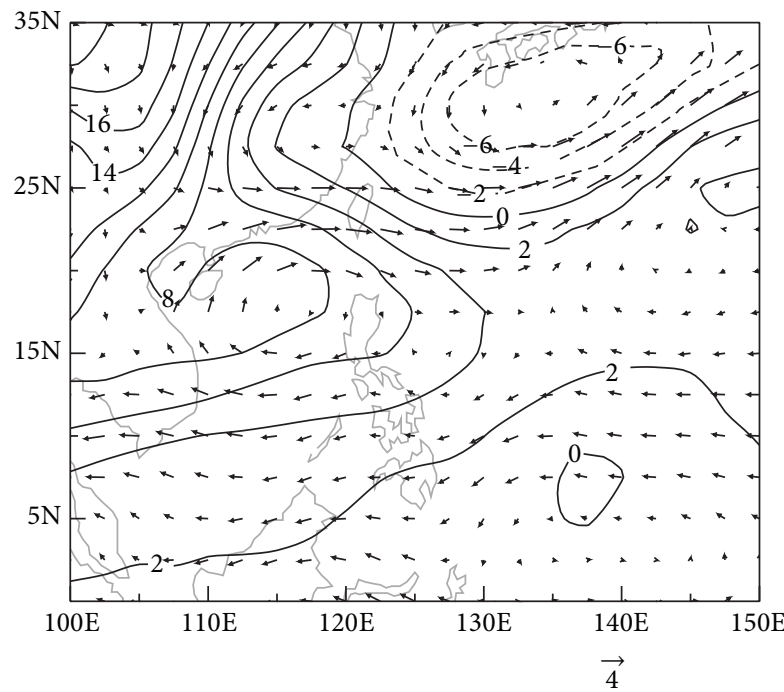

(a)

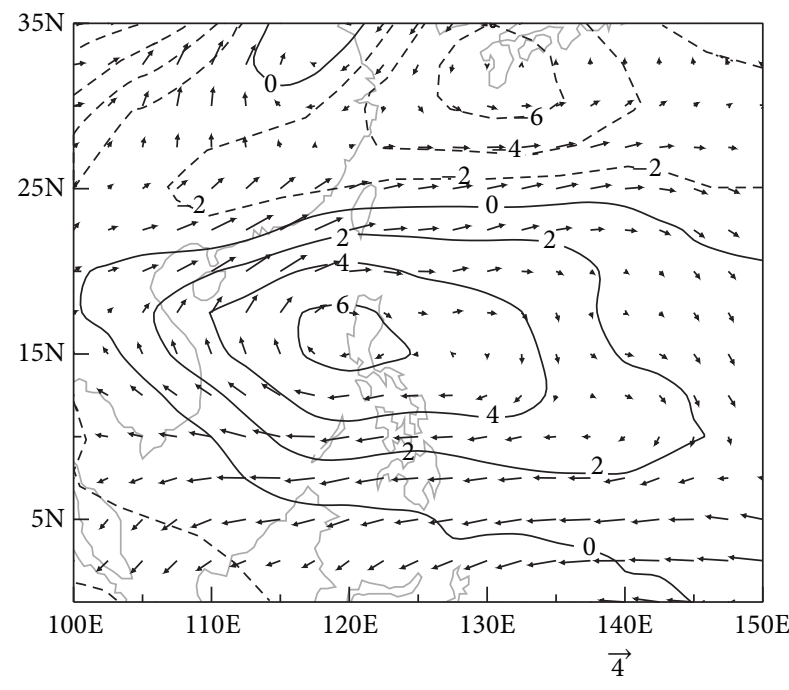

(b)

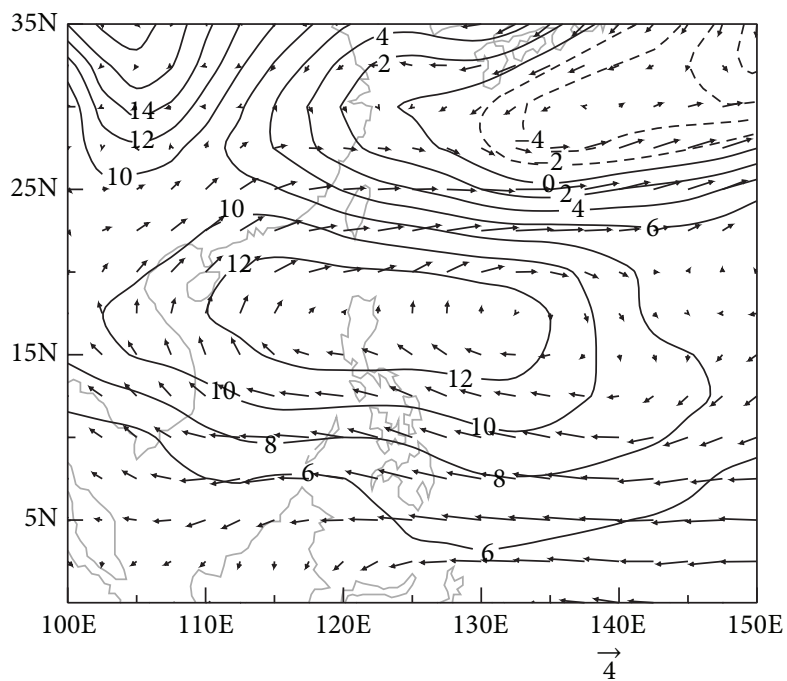

(c)

FIgURE 6: Same as Figure 5, but for the composite of wind vector anomalies $\left(\mathrm{m} \mathrm{s}^{-1}\right)$ and geopotential height anomalies in $850 \mathrm{hPa}($ dagpm).

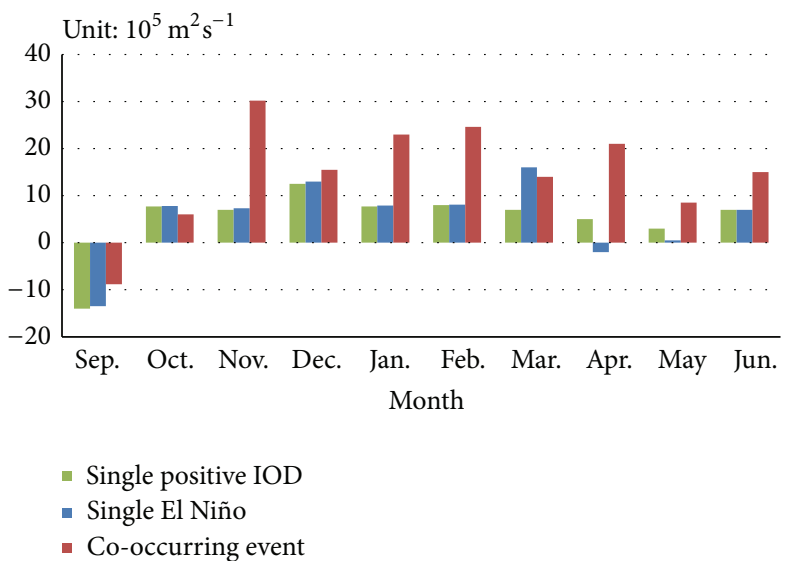

Figure 7: Same as Figure 5, but for the composite of month streamfunction anomalies at $850 \mathrm{hPa}\left(10^{5} \mathrm{~m}^{2} \mathrm{~s}^{-1}\right)$ over $\left(120-150^{\circ} \mathrm{E}, 10-20^{\circ} \mathrm{N}\right)$. 


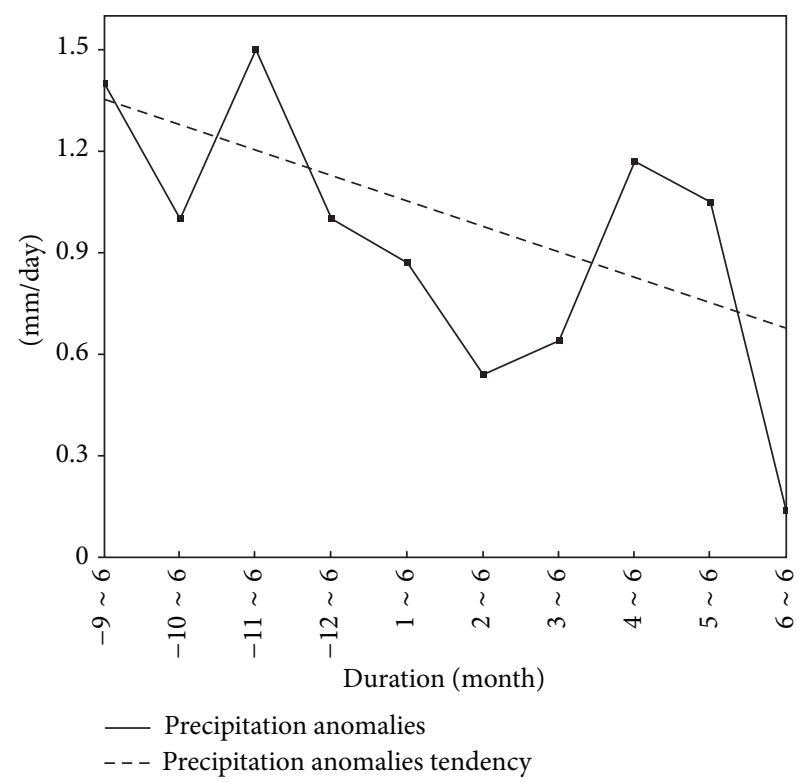

(a)

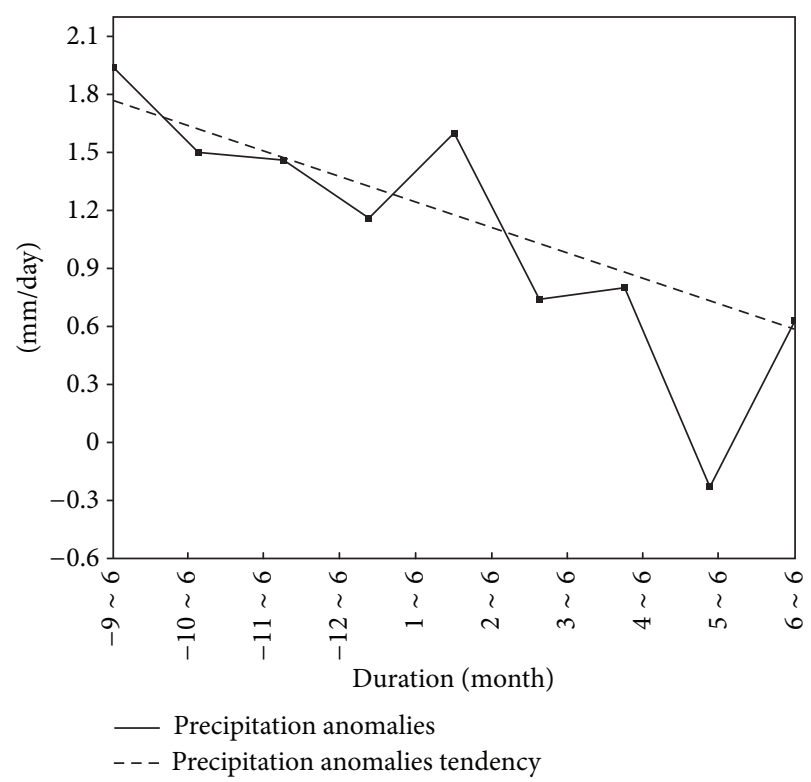

(b)

FIGURE 8: Area-mean precipitation anomalies over YRBS in June resulted from the effect of the input SSTA with different durations over TP and TIO regions: (a) SEXP1-PE and (b) SEXP1-PI (mm day $\left.{ }^{-1}\right)$. The $x$-axis shows the SSTA durations from September to next June (-9 6), from November to next June $(-11 \sim 6), \ldots$ from May to June, and only in June, respectively.

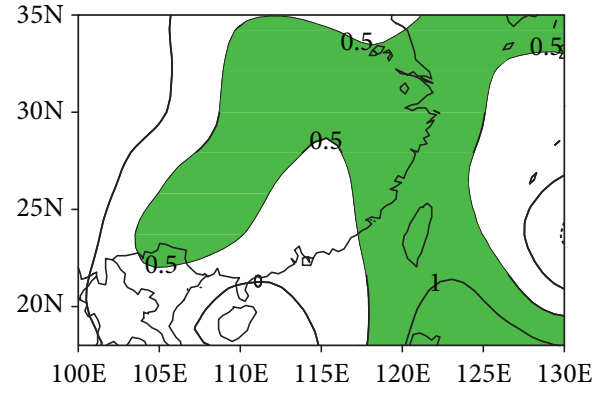

(a)

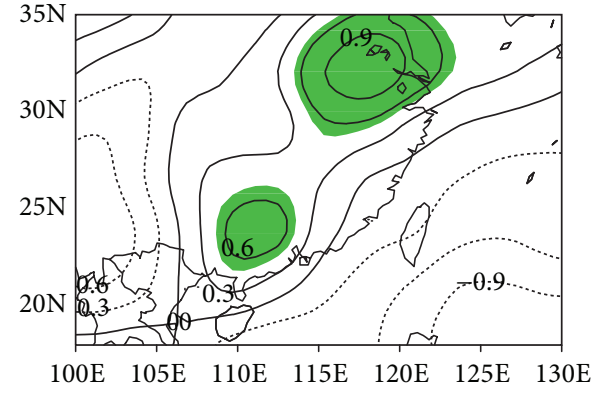

(b)

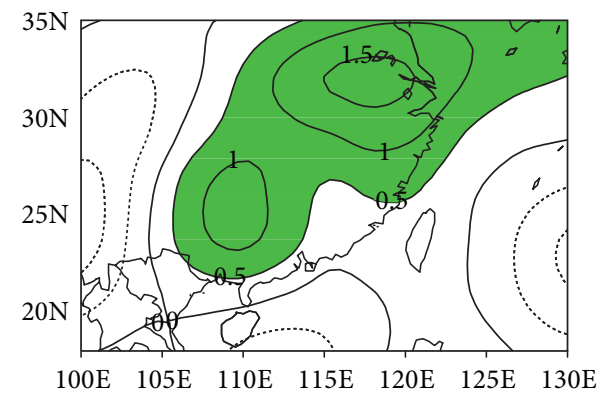

(c)

FIGURE 9: The simulated precipitation anomalies in June over South China in (a) SEXP1-PE, (b) SEXP1-PI, and (c) SEXP3-PEI (shaded area denotes precipitation anomaly exceeding $0.5 \mathrm{~mm} \mathrm{day}^{-1}$ ).

at $\left(112^{\circ} \mathrm{E}, 19^{\circ} \mathrm{N}\right)$ and $\left(115^{\circ} \mathrm{E}, 17^{\circ} \mathrm{N}\right)$, respectively, in $\mathrm{PE}$ and PI years, which were favorable for increased precipitation in June over YRBS $[23,24]$. All of the Z850A centers were accompanied with a PSAC in Figures 6(a) and 6(b). The anomalous southwesterlies that flowed out from PSAC could be found over YRBS in Figures 6(a) and 6(b) too. Since the PSAC could result in anomalously wet conditions along East Asia, precipitation over the YRBS in June tends to be increase. However, when the PEI event matured in the preceding boreal autumn, the Z850A near the Philippines were much 


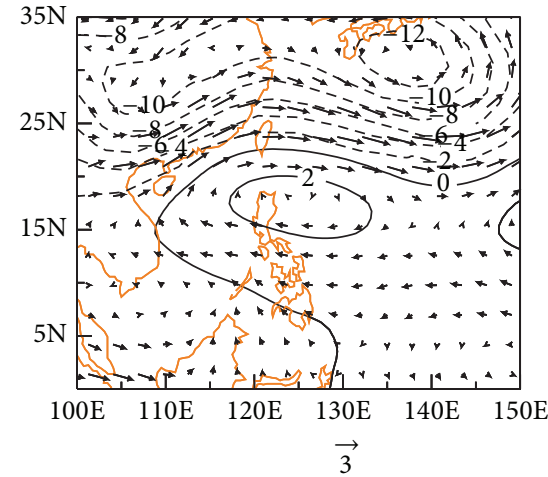

(a)

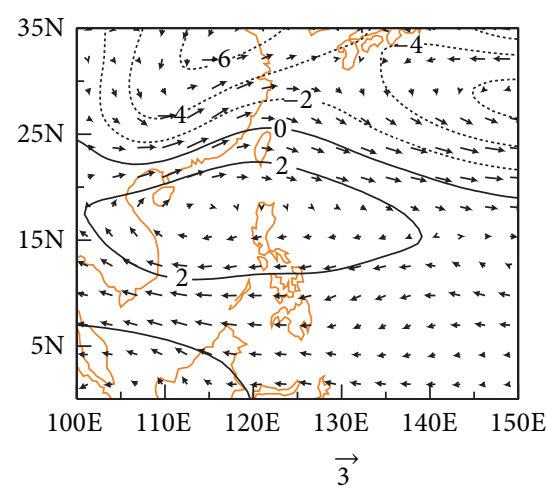

(b)

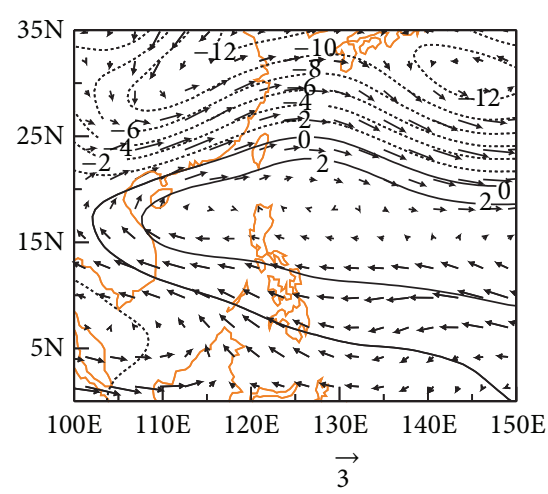

(c)

FIGURE 10: Same as Figure 9, but for the simulated wind vector anomalies $\left(\mathrm{m} \mathrm{s}^{-1}\right)$ and geopotential height anomalies in $850 \mathrm{hPa}($ dagpm).

stronger and the amplitude of the Z850A in Figure 6(c) was about 4 dagpm higher than that in Figures 6(a) and 6(b). Also, the PSAC was much stronger with the center located around $\left(125^{\circ} \mathrm{E}, 17^{\circ} \mathrm{N}\right)$ and farther northeastward compared with that in Figures 6(a) and 6(b). These implied that previous co-occurring events tended to produce stronger PSAC that played a role in transporting more water vapor to YRBS and resulting in more rainfall there in June than a previous single event did. Figure 7 showed the temporal evolutions of the anomalous streamfunction averaged over the Philippine Sea $\left(120-150^{\circ} \mathrm{E}, 10-20^{\circ} \mathrm{N}\right)$ at $850 \mathrm{hPa}(\mathrm{S} 850)$, composed from PE years, PI years, and PEI years, respectively. Positive S850 means strong PSAC occurring. It is usually seen that the PSAC largely developed in the matured period of the events and maintained its strength until next June as shown in Figure 7. And, when both El Niño and P-IOD matured in boreal autumn, the PSAC was stronger and even sustained for a longer time than those in the case of the single event.

\section{Simulations of the Effects Generated by Previous PE and PI Events}

By using CAM3.0, sensitivity experiments of SEXP1-PE and SEXP1-PI were conducted to study the impacts of the previous El Niño and P-IOD events that matured in boreal autumn on the rain enhanced YRBS that occurred in June, respectively. The precipitation anomalies over YRBS in June result from the effect of an El Niño and P-IOD event with different durations in experiments SEXP1-PE and SEXP1PI were produced (Figure 8 ). The anomalous precipitation had a decreased trend with reduced durations of imposed P-SSTA only over TP (TIO) as shown in those figures. These were important evidence that the El Niño and PIOD event in preceding boreal autumn could significantly cause positive rain-YRBS and provide a delayed impact on it. In order to study the stability and validity of simulation results above, we further conducted the second round of sensitivity experiments SEXP2-PE and SEXP2-PI to simulate the precipitation anomalies in response to different intensity of P-SSTA over TP and TIO persistent from September to next June, respectively (figures omitted). There were positive
rain-YRBS anomalies when strong or weak SSTAs imposed over TP or TIO from September to next June. The positive rain-YRBS anomalies were increased with the increasing intensity of the SSTAs imposed over TP or TIO, which supports the observational results. These also implied that the model was sensitive to the SSTAs over TP or TIO and the simulations were stable.

In SEXP3-PEI, the P-SSTA was imposed both over TP and TIO and the model was integrated from September to next June. The experiment showed that there were positive rainYRBS anomalies with the center above $1 \mathrm{~mm}^{-1 a y}{ }^{-1}$ at $\left(118^{\circ} \mathrm{E}\right.$, $32^{\circ} \mathrm{N}$ ) and $\left(109^{\circ} \mathrm{E}, 25^{\circ} \mathrm{N}\right.$ ) (Figure 9(c)). In SEXP1-PE (SEXP1$\mathrm{PI}$ ), one of the experiments was carried out by imposing P-SSTA only over TP (TIO) from September to next June. The positive rain-YRBS anomalies with the values about $0.5 \mathrm{~mm} \mathrm{day}^{-1}$ are shown in Figure 9(a). The positive rainfall anomalies centers above $0.6 \mathrm{~mm}$ day $^{-1}$ were at $\left(118^{\circ} \mathrm{E}, 32^{\circ} \mathrm{N}\right)$ and $\left(111^{\circ} \mathrm{E}, 22^{\circ} \mathrm{N}\right)$ in Figure $9(\mathrm{~b})$. Rain-YRBS anomalies in SEXP1-PE and SEXP1-PI were much weaker than these in SEXP3-PEI. Here, in order to investigate if the simulation coincides with composites, we showed the Z850A and wind vector anomalies in June after imposing the SSTAs to PE, PI, and PEI events previously (Figure 10). There were anomalous PSAC in the experiments SEXP1-PE, SEXP1-PI, and SEXP3PEI with the Z850A of 2 dagpm. However, the area covered with above 2 dagpm near the Philippines in Figure 10(c) was the largest compared with those in Figures 10(a) and 10(b). This implies that PSAC would be stronger when both events co-occurred. The stronger southwesterlies over YRBS were found in Figure 10(c). All of the simulation results roughly coincide with observations.

The simulations and statistical analyses strongly indicated that the combined influence of a PEI event that matured in boreal autumn on rain-YRBS in next June was substantially larger than that of the single event.

\section{Summary and Discussions}

Using observational analysis and simulation, influences of El Niño and the P-IOD event in preceding boreal autumn on rain-YRBS were investigated. The most significant correlation 


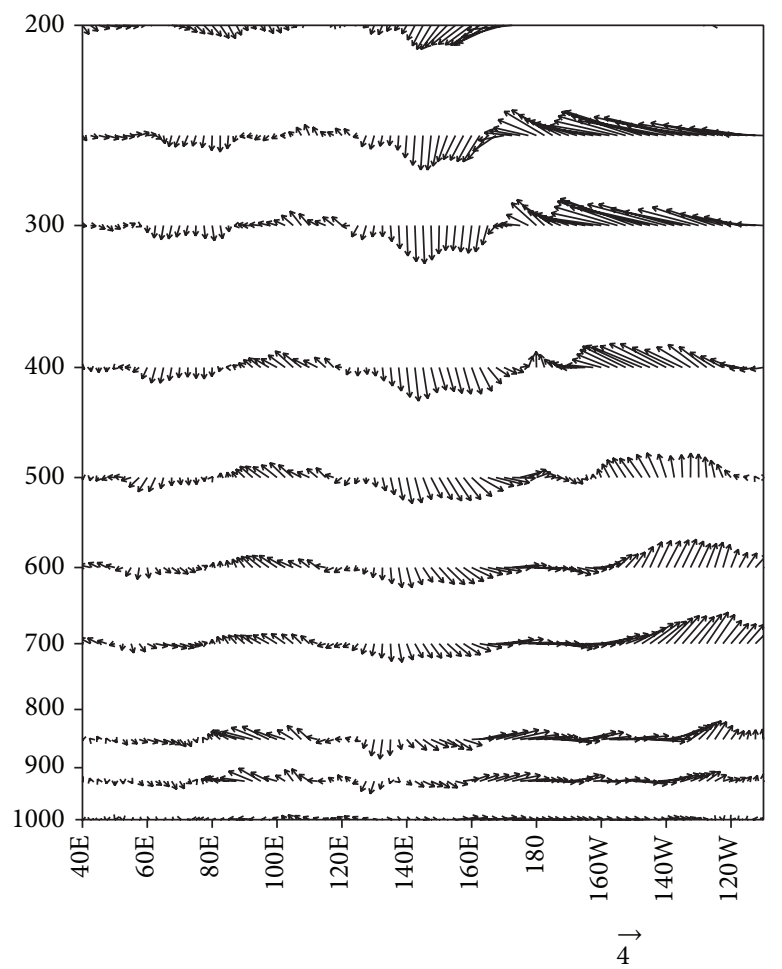

(a)

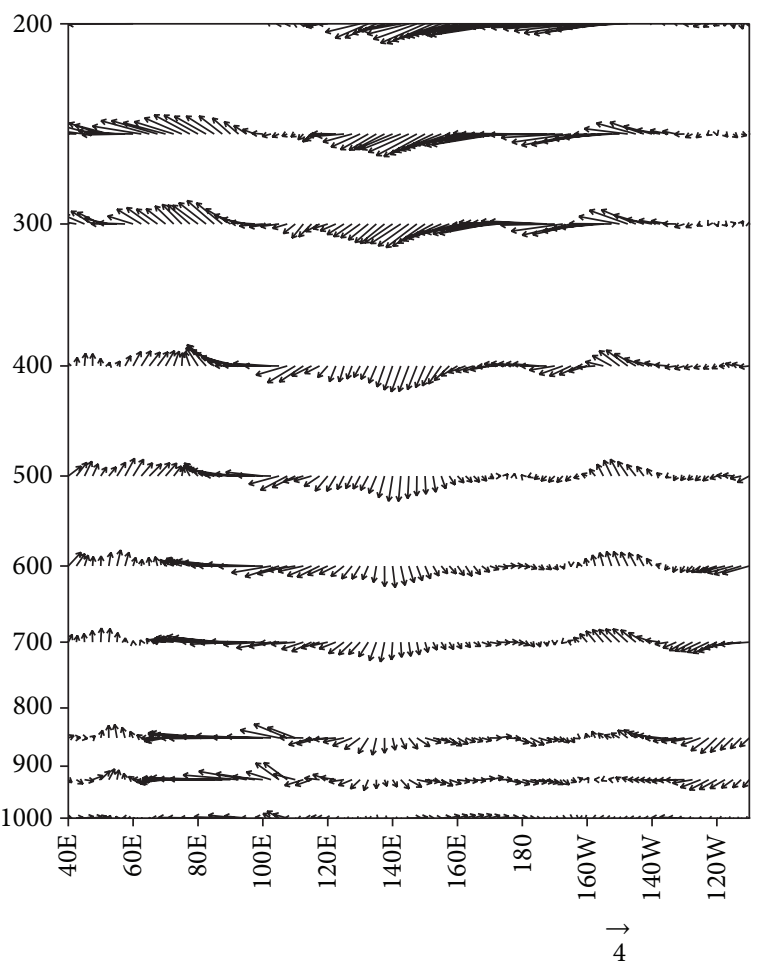

(b)

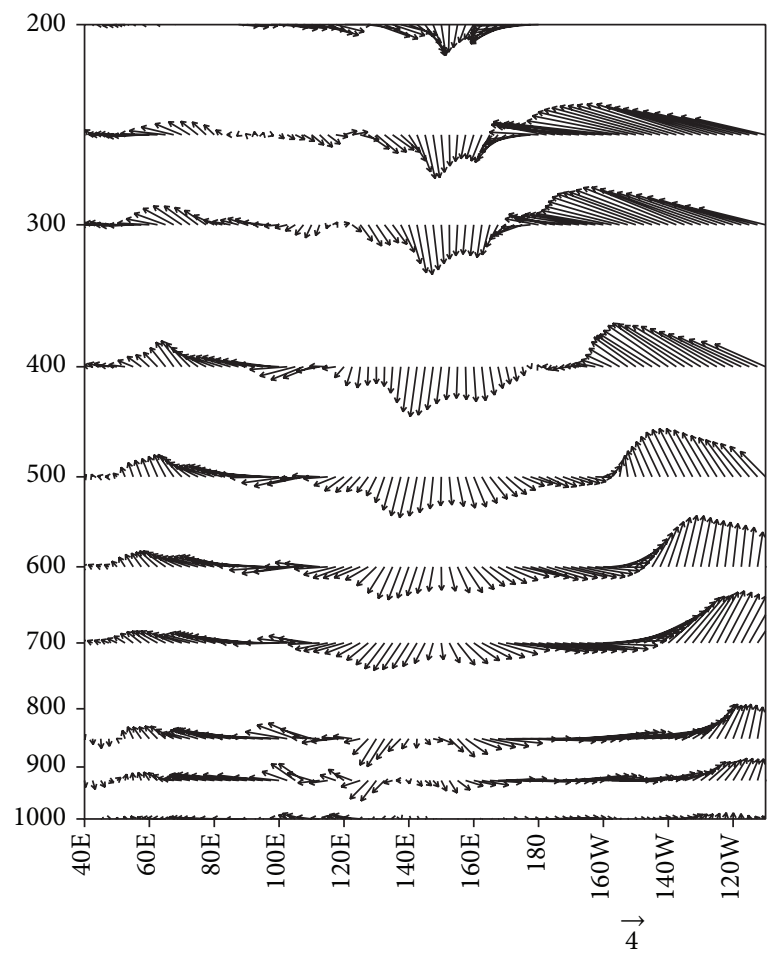

(c)

Figure 11: Composite of anomalous zonal-vertical circulation averaged in $5^{\circ} \mathrm{S}-5^{\circ} \mathrm{N}$ (vertical wind velocity: Pa s${ }^{-1}$; zonal wind: $\mathrm{m} \mathrm{s}^{-1}$ ) over tropical Pacific and Indian Ocean in boreal autumn of (a) single El Niño years: 1965, 1976, and 1991; (b) single P-IOD years: 1961, 1967, and 1994; (c) and the El Niño and P-IOD co-occurring years: 1963, 1972, 1982, 1987, and 1997. 
(about 0.523 , exceeding 95\% confidence level) between the IODI and NINO3 appeared in boreal autumn of the 20th century. ENSO and P-IOD would inevitably interact with each other via the atmospheric east-west Walker circulation over TP and TIO. For example, a strongly developing anticyclonic circulation over the SETIO may give positive feedback to the neighboring circulation over the western Pacific and vice versa. The interaction between the two events should be further studied in the future. The NINO3 and IODI have significant correlations in boreal fall. Thus, IODN3 which measures the intensity of ENSO and IOD events was created to estimate the combined effect. All of the three indexes in the boreal fall were positively correlated with the rain-YRBS. The co-occurring events were most significantly correlated with the rain-YRBS. The climatic simulations roughly coincided with the diagnostic analysis, although there were slight differences between them. Simulations and statistical analyses strongly indicated that previous PEI events tended to produce stronger PSAC. The stronger PSAC generated by the two events can play a role in transporting more water vapor to YRBS, resulting in more rainfall there in June than that caused by a previous single event.

When a P-IOD event occurs with El Niño in mature phase, the influence on the rain enhanced YRBS that occurred was amplified through a mechanism of a stronger developing PSAC. The significant negative SSTAs over the SETIO and the tropical west Pacific (TWP), when both events matured in boreal autumn, could induce negative anomalous Walker circulations averaged over $5^{\circ} \mathrm{S}-5^{\circ} \mathrm{N}$ in the tropical IndoPacific (Figure 11(c)), although the intensity of the SSTAs over TIO and TP could be gradually decreased with time. A sinking branch over TWP-Maritime Continent was substantially intensified in this case, which appeared as a part of the AntiWalker circulation. The anomalous subsidence over TWPMaritime Continent also appeared in both single El Niño (Figure 11(a)) and single P-IOD (Figure 11(b)) plots, but the interaction was weaker. Thus, the effect of convection on both events was suppressed to a greater degree and caused drier conditions over TWP-Maritime Continent than single events did. In terms of Gill-Matsuno dynamics $[25,26]$, the anticyclone as a Rossby wave response should occur to the northwest of the suppressed precipitation (Figure 6). As a result, a stronger PSAC was induced which could persist from boreal fall to the ensuing boreal summer (Figure 6(c)), transporting more water vapor and causing abundant rain enhanced YRBS. Consistent with the observational results, the simulations also suggest that the P-IOD event could weaken the Indian Ocean-Walker circulation and when PIOD occurred with El Niño the anomalous subsidence over TWP-Maritime Continent was enhanced (figure omitted). Since the combined impact of the PEI events, the anomalous PSAC in Figure 10(c) became much stronger and further westward shift that that in Figure 10(a).

The CAM3.0 in this study properly simulated the response of rain enhanced YRBS that occurred in the SSTAs over the central TP and TIO. The ocean-atmosphere processes are crucial in the monsoon region and the atmospheric feedback on SST may be important. Thus, we consider using Coupled Ocean-Atmosphere General Circulation Model to confirm our conclusions in this study and to better understand the delayed effect of the two events on the East Asian monsoon in the future.

\section{Conflict of Interests}

The authors declare that there is no conflict of interests regarding the publication of this paper.

\section{Acknowledgments}

The authors give many thanks to Professor Dong Min for insightful comments on running the CAM3.0 model and the related methods. The authors thank three anonymous reviewers for their valuable suggestions and comments. This study was supported jointly by the program of National Natural Science Foundation of China (nos. 41106004, 41106159, 41206013, 41375091 and 41376014), the National Marine Public Welfare Research Project of China (no. 201005019), the Project of the Ministry of Science and Technology of China (no. 2012CB417202) and the Special Fund of Laboratory of Severe Weather of China.

\section{References}

[1] Y. Wang, B. Wang, and J.-H. Oh, "Impact of the preceding EL Niño on the East Asian summer atmosphere circulation," Journal of the Meteorological Society of Japan, vol. 79, no. 1, pp. 575-588, 2001.

[2] B. Wang, R. Wu, and X. Fu, "Pacific-East Asian teleconnection: how does ENSO affect East Asian climate?" Journal of Climate, vol. 13, no. 9, pp. 1517-1536, 2000.

[3] N. H. Saji, B. N. Goswami, P. N. Vinayachandran, and T. Yamagata, "A dipole mode in the tropical Indian Ocean," Nature, vol. 401, no. 6751, pp. 360-363, 1999.

[4] P. J. Webster, A. M. Moore, J. P. Loschnigg, and R. R. Leben, "Coupled ocean-atmosphere dynamics in the Indian Ocean during 1997-98," Nature, vol. 401, no. 6751, pp. 356-360, 1999.

[5] B. Xiang, W. Yu, T. Li, and B. Wang, "The critical role of the boreal summer mean state in the development of the IOD," Geophysical Research Letters, vol. 38, no. 2, Article ID L02710, 2011.

[6] A. F. Bracco, F. Kucharski, F. Molteni, W. Hazeleger, and C. Severijns, "A recipe for simulating the interannual variability of the Asian summer monsoon and its relation with ENSO," Climate Dynamics, vol. 28, no. 5, pp. 441-460, 2007.

[7] K. Ashok, Z. Guan, and T. Yamagata, "Impact of the Indian Ocean dipole on the relationship between the Indian monsoon rainfall and ENSO," Geophysical Research Letters, vol. 28, no. 23, pp. 4499-4502, 2001.

[8] K. Ashok, Z. Guan, N. H. Saji, and T. Yamagata, "Individual and combined influences of ENSO and Indian Ocean dipole on the Indian summer monsoon," Journal of Climate, vol. 17, no. 16, pp. 3141-3155, 2004.

[9] N. H. Saji and Y. Yamagata, "Structure of SST and surface wind variability during Indian Ocean dipole mode events: COADS observations," Journal of Climate, vol. 16, no. 16, pp. 2735-2751, 2003. 
[10] J.-J. Luo, R. Zhang, S. K. Behera et al., "Interaction between El Niño and extreme Indian Ocean dipole," Journal of Climate, vol. 23, no. 3, pp. 726-742, 2010.

[11] J. J. Luo, W. Sasaki, and Y. Masumoto, "Indian Ocean warming modulates Pacific climate change," Proceedings of the National Academy of Sciences of the United States of America, vol. 109, no. 46, pp. 18701-18706, 2012.

[12] N. H. Saji and T. Yamagata, "Possible impacts of Indian Ocean dipole mode events on global climate," Climate Research, vol. 25, no. 2, pp. 151-169, 2003.

[13] J.-J. Luo, S. Behera, Y. Masumoto, H. Sakuma, and T. Yamagata, "Successful prediction of the consecutive IOD in 2006 and 2007," Geophysical Research Letters, vol. 35, no. 14, Article ID L14S02, 2008.

[14] F. A. Schott, S. P. Xie, and J. McCreary, "Indian Ocean circulation and climate variability," Reviews of Geophysics, vol. 47, no. 1, Article ID RG1002, 2009.

[15] C. Y. Li and M. Q. Mu, "The influence of the Indian Ocean dipole on atmospheric circulation and climate," Advances in Atmospheric Sciences, vol. 18, no. 5, pp. 831-843, 2001.

[16] Z. Guan and T. Yamagata, "The unusual summer of 1994 in East Asia: IOD teleconnections," Geophysical Research Letters, vol. 30, no. 10, pp. 1544-1548, 2003.

[17] M. Hashizume, L. F. Chaves, and N. Minakawa, "Indian Ocean dipole drives malaria resurgence in East African highlands," Scientific Reports, vol. 2, article 269, 2012.

[18] R. Kistler, E. Kalnay, W. Collins et al., "The NCEP-NCAR 50year reanalysis: monthly means CD-ROM and documentation," Bulletin of the American Meteorological Society, vol. 82, no. 2, pp. 247-268, 2001.

[19] H. Yang, X. L. Jia, and C. Y. Li, "The tropical Pacific-Indian Ocean temperature anomaly mode and its effect," Chinese Science Bulletin, vol. 51, no. 23, pp. 2878-2884, 2006.

[20] A. Kaplan, M. A. Cane, Y. Kushnir, A. C. Clement, M. B. Blumenthal, and B. Rajagopalan, "Analyses of global sea surface temperature 1856-1991," Journal of Geophysical Research, vol. 103, no. C9, pp. 18567-18589, 1998.

[21] W. D. Collins, P. J. Rasch, B. A. Boville et al., "Description of NCAR community atmosphere model (CAM3.0)," Tech. Rep. NCAR/TN-464+STR, National Center for Atmospheric Research, Boulder, Colo, USA, 2004.

[22] A. Cherchi and A. Navarra, "Influence of ENSO and of the Indian Ocean dipole on the Indian summer monsoon variability," Climate Dynamics, vol. 41, no. 1, pp. 81-103, 2013.

[23] Y. Wang, "Effects of blocking anticyclones in Eurasia in the rainy season (Meiyu/Baiu season)," Journal Meteorological Society of Japan, vol. 70, no. 2, pp. 929-951, 1992.

[24] Q. Y. Zhang and S. Y. Tao, "Influence of Asian mid-high latitude circulation on East Asian summer rainfall," Acta Meteorologica Sinica, vol. 56, no. 2, pp. 199-211, 1998.

[25] T. Matsuno, "Quasi-geostrophic motions in the equatorial area," Jounary of Meteorological Society of Japan, vol. 44, no. 1, pp. 2543, 1966.

[26] A. E. Gill, "Some simple solutions for heat-induced tropical circulation," Quarterly Journal of the Royal Meteorological Society, vol. 106, no. 449, pp. 447-462, 1980. 

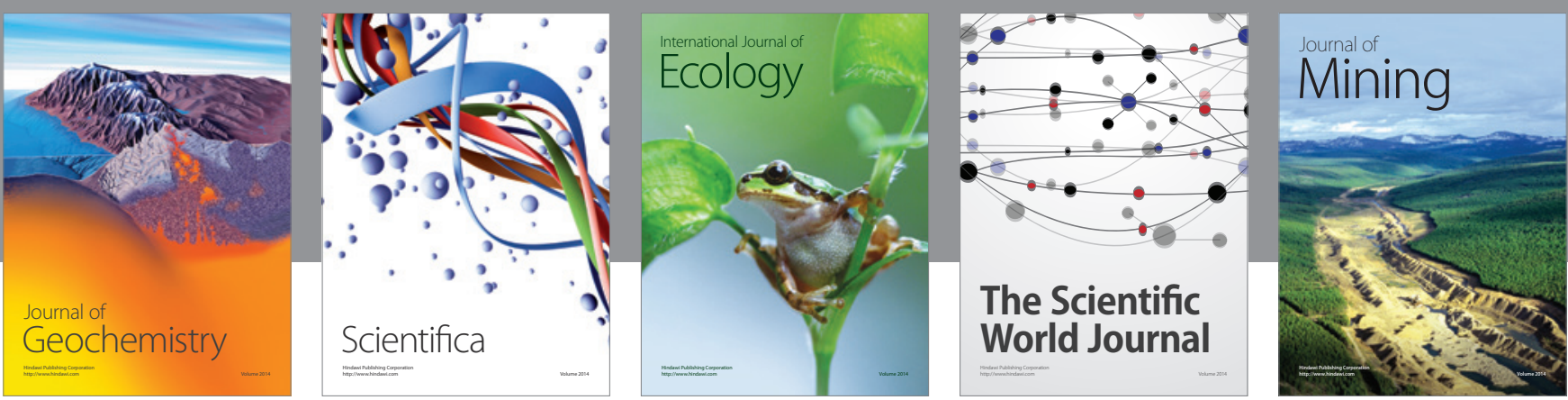

The Scientific World Journal
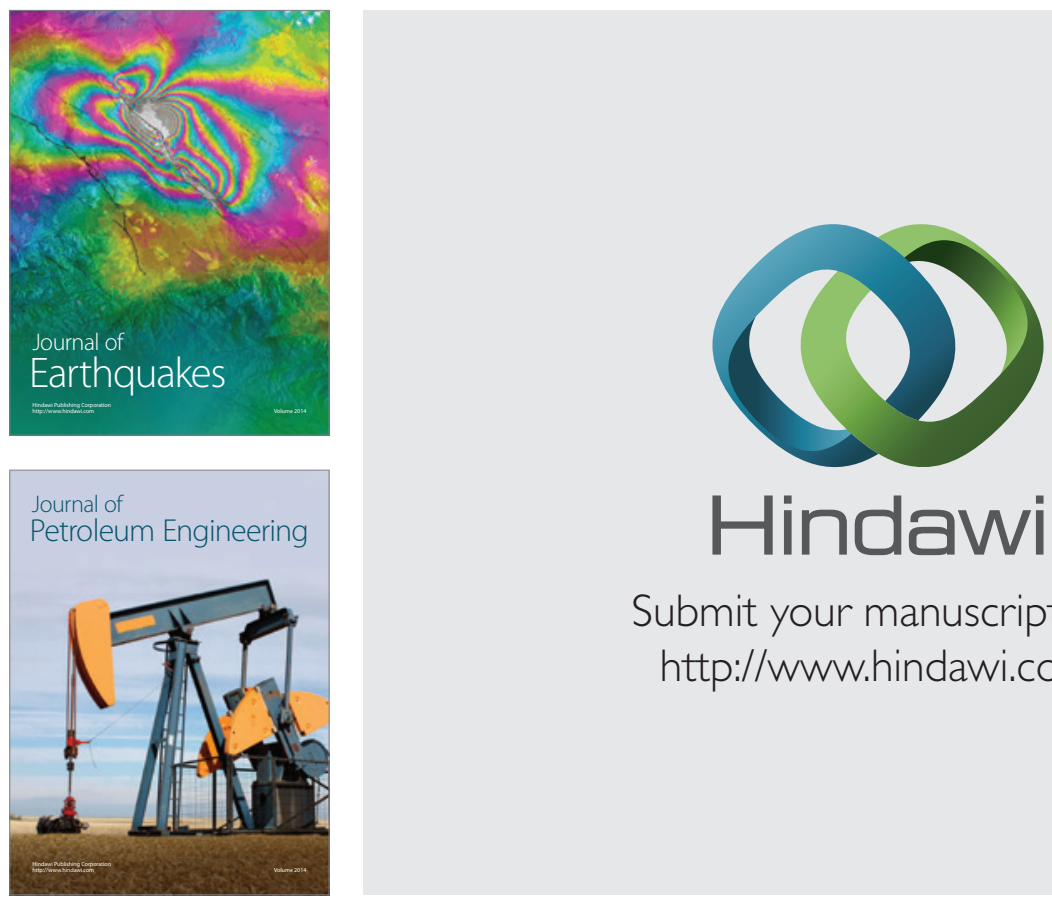

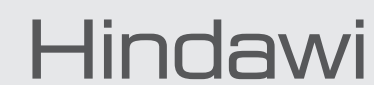

Submit your manuscripts at

http://www.hindawi.com
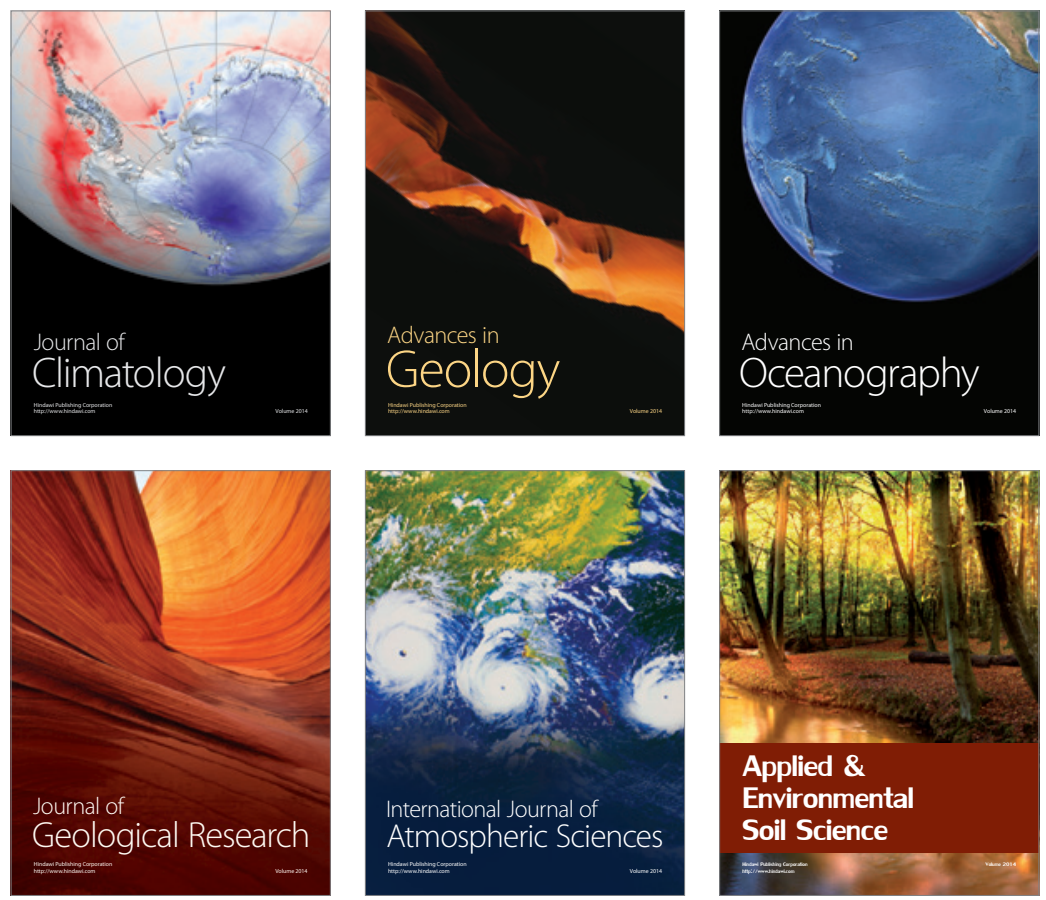
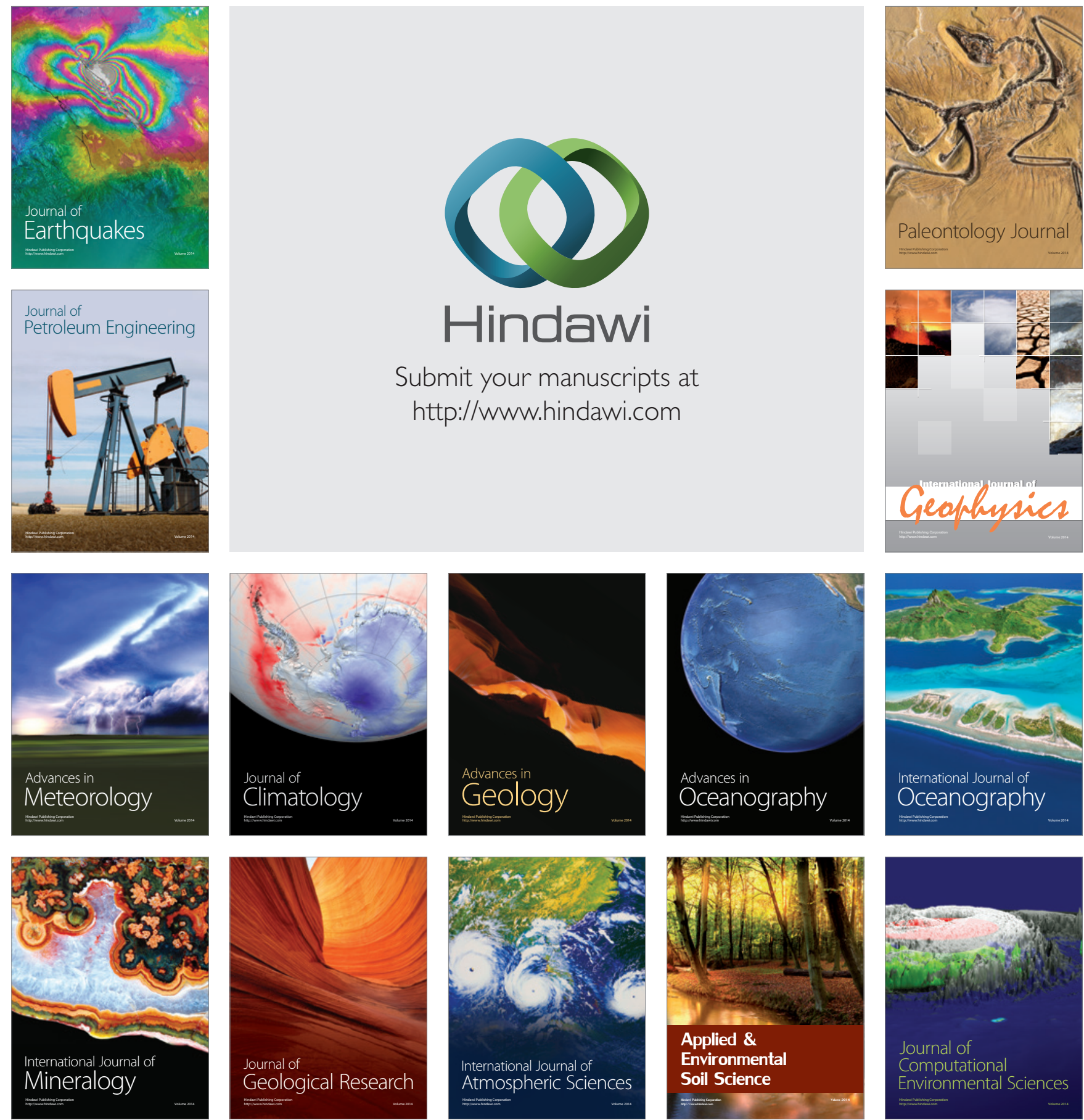